\title{
LA GESTIÓN DEL PATRIMONIO ARQUEOLÓGICO DE LA PONTIFICIA UNIVERSIDAD CATÓLICA DEL PERÚ ${ }^{[*]}$
}

\section{THE MANAGEMENT OF THE ARCHAEOLOGICAL HERITAGE OF THE PONTIFICIA UNIVERSIDAD CATÓLICA DEL PERÚ}

\author{
ANDREA BRINGAS HEREDIA ${ }^{(x)}$ \\ Pontificia Universidad Católica del Perú (Perú) \\ andreabringas@gmail.com \\ Fecha de recepción: 25 de marzo de 2018 \\ Fecha de aprobación: 19 de junio de 2018
}

\section{RESUMEN}

Los sitios arqueológicos ubicados en el interior del campus de la Pontificia Universidad Católica del Perú forman parte de un extenso complejo prehispánico que, a diferencia de otros sitios que existieron en Lima Metropolitana, lograron ser parcialmente conservados. Esto se debió, principalmente, al trabajo de personas comprometidas con el patrimonio como la doctora Josefina Ramos de Cox y otros miembros del Seminario de Arqueología de dicha universidad. Las acciones iniciales de gestión de ese patrimonio, conformado por la Huaca 20, la Huaca 64 y el Camino Inca, estuvieron relacionadas a la defensa y la protección, y la investigación, mientras que las acciones recientes han estado orientadas al rescate y la puesta en valor de los monumentos, tareas que se han llevado a cabo gracias a voluntades políticas y compromisos institucionales. El siguiente artículo tiene como objetivo presentar la experiencia de gestión del patrimonio arqueológico de la universidad, que se abordará en el marco de la normativa, valores y funciones. Se evaluará, además, los logros vinculados al ejercicio de los compromisos mencionados, y se propondrá desafíos relacionados a la integración del patrimonio arqueológico en la vida cotidiana de la comunidad universitaria.

\section{PALABRAS CLAVE}

Gestión del patrimonio arqueológico, universidad, logros y desafíos

\section{ABSTRACT}

The archaeological sites located inside the campus of the Pontifical Catholic University of Peru (PUCP) are part of an extensive pre-Hispanic complex that, unlike other sites that existed in Metropolitan Lima, managed to be partially conserved. It occurred mainly due to the work of people committed to heritage such as Dr. Josefina Ramos de Cox and other members of the Archeology Seminary of the university. The initial management actions taken towards this piece of heritage, consisting of Huaca 20, Huaca 64 and the Inca Trail, were related to defense, protection and research. On the other hand, recent actions have been associated to the rescue and enhancement of the monuments, tasks that have been carried out thanks to political will institutional commitment. The following article aims to present the experience of the management of the university's archaeological heritage, which will be considered on the basis of normative frameworks, values and functions. Likewise, it evaluates achievements linked to the exercise of the above-mentioned commitments, and proposes challenges related to the integration of archaeological heritage to the daily life of the PUCP community..

\section{KEYWORDS}

Management of archaeological heritage, university, achievements and challenges

${ }^{*}$ ) Se agradece la asesoría, revisión y aportes de la Dra. Inés Del Águila y del MSc. José Hayakawa, así como el acceso a la información proporcionada por la Oficina de Obras y Proyectos de la Dirección de Infraestructura de la Pontificia Universidad Católica del Perú (PUCP).

(**) Licenciada en Arqueología por la PUCP, con estudios en Relaciones Comunitarias y Responsabilidad Social en la Universidad ESAN. Tiene experiencia en proyectos de intervención arqueológica, incidencia política, relaciones comunitarias, y ha realizado diversas consultorías para los sectores público y privado. En la actualidad, se desempeña como arqueóloga del campus de la PUCP a cargo de la gestión de los proyectos patrimoniales. 
La gestión integral del patrimonio arqueológico no se limita a su preservación y conservación, sino que involucra una dimensión social que responde al vínculo del patrimonio con asuntos fundamentales como ciudadanía, identidad y desarrollo. La presencia de más de 500 fragmentos de monumentos prehispánicos en la traza urbana de Lima Metropolitana, una ciudad multicultural de 10 millones de habitantes entre los que existen profundas inequidades, caracterizada por un crecimiento urbano desordenado, presenta considerables desafíos en cuanto a su gestión.

Entre aquellos sitios arqueológicos que han sobrevivido al paso del tiempo en Lima, se encuentran aquellos correspondientes al Complejo Urbano Prehispánico Maranga, situado en los terrenos del zoológico Parque de las Leyendas, y los campus de la Universidad Nacional Mayor de San Marcos (UNMSM) y la Pontificia Universidad Católica del Perú (PUCP). La presencia de estos sitios supone responsabilidades y la necesidad de respuestas institucionales de parte de estos organismos. El presente artículo tiene como objetivo exponer la experiencia de gestión del patrimonio arqueológico ubicado en el interior del campus de la PUCP, conformado por tres sitios: la Huaca 20, la Huaca 64 y el Camino Inca. Para ello, luego de exponer brevemente sobre la cantidad y concentración de sitios prehispánicos en Lima Metropolitana, y sobre el Complejo Maranga, se hará referencia a los marcos institucionales de la gestión del patrimonio desde la perspectiva de la institución universitaria, teniendo en cuenta el concepto de uso social, las categorías de valores, y las funciones de las instituciones responsables del patrimonio propuestas por Ballart y Tresserras (2001). Asimismo, se aplicará algunos conceptos y aspectos de la gestión del patrimonio arqueológico expresados en documentos internacionales y en Pérez-Juez (2010).

Cabe destacar el rol decisivo de miembros y unidades de la PUCP en la defensa e investigación del patrimonio arqueológico de la universidad durante la década de 1960. A partir de esos primeros trabajos, la universidad inició una relación oscilante con su patrimonio. En las décadas de 1990 y 2000 se realizaron nuevas investigaciones llevadas a cabo por docentes y estudiantes. Desde la década de 2010, se han desarrollado otras intervenciones, como rescates arqueológicos y proyectos de puesta en valor vinculados a la difusión y al acondicionamiento de los monumentos para el uso y disfrute de la comunidad universitaria. En el marco de políticas, voluntades y apuestas institucionales se describen los diversos proyectos e iniciativas desarrolladas por la PUCP en los tres sitios arqueológicos mencionados.

\section{El patrimonio arqueológico de Lima Metropolitana y el Complejo Maranga}

En el artículo 1 de la Carta Internacional para la Gestión del Patrimonio Arqueológico (CIGPA) se expresa lo siguiente:

El "patrimonio arqueológico" representa la parte de nuestro patrimonio material para la cual los métodos de la arqueología nos proporcionan la información básica. Engloba todas las huellas de la existencia del hombre y se refiere a los lugares donde se ha practicado cualquier tipo de actividad humana, a las estructuras y los vestigios abandonados de cualquier índole, tanto en la superficie, como enterrados, o bajo las aguas, así como al material relacionado con los mismos. (1990, p. 2)

La ciudad de Lima es un territorio con un patrimonio arqueológico milenario que, a lo largo del tiempo, se ha visto transformado en fragmentos de historia materializada ${ }^{1}$ dentro del actual trazado urbano. Adicionalmente a la definición propuesta por la $\mathrm{Cl}$ GPA, es pertinente considerar la anotación de Pérez-Juez (2010) acerca del patrimonio arqueológico: "es un valor, atributo o reconocimiento que asignamos desde el presente.

\footnotetext{
1. Siguiendo la noción de patrimonio que proponen Ballart y Tresserras (2001), referida a la permanencia en el tiempo de los objetos patrimoniales.
} 


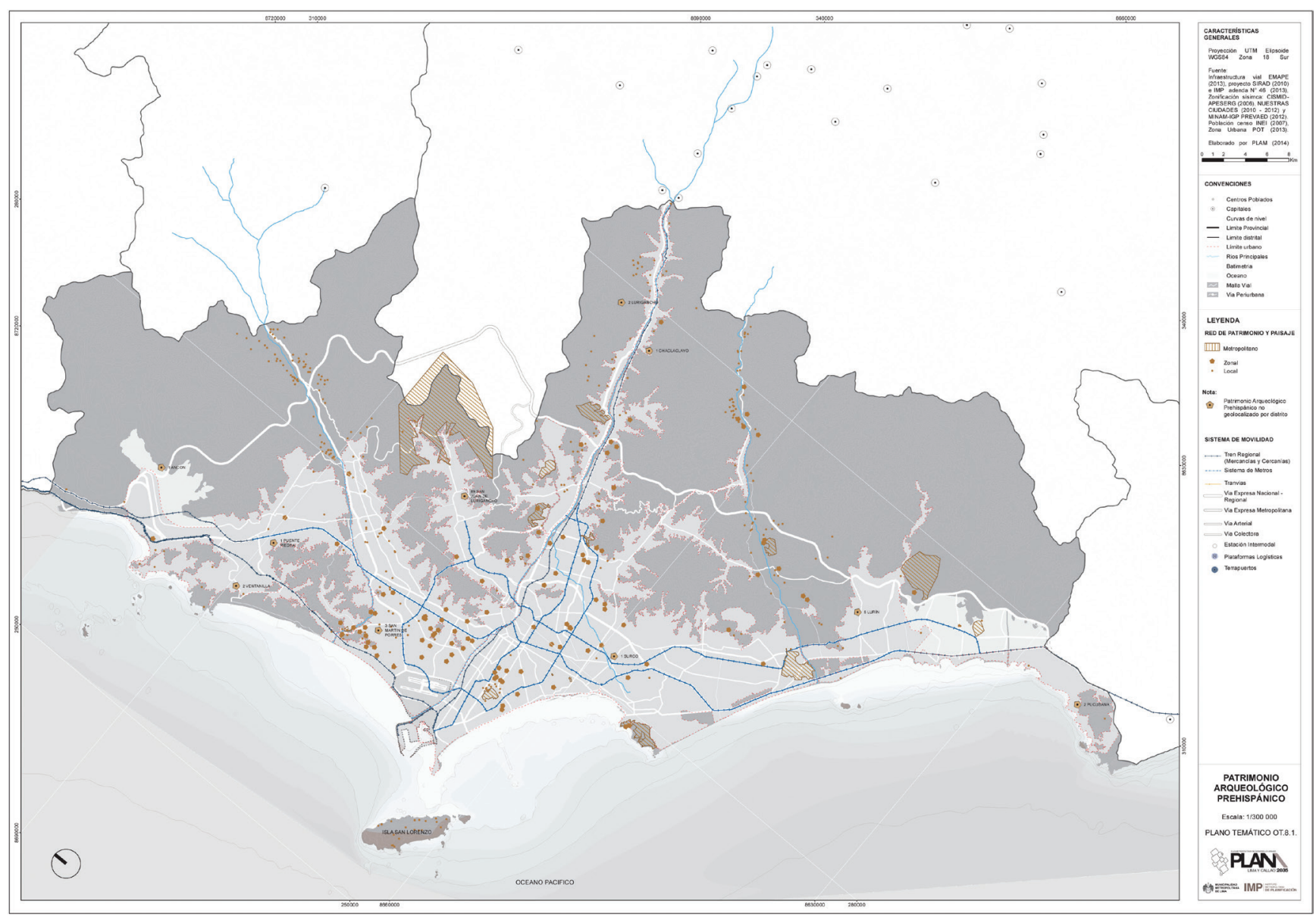

Figura 1. Patrimonio Arqueológico Prehispánico en Lima Metropolitana. En "Patrimonio y Plan Urbano en Lima: Apuestas y Desafíos del Diagnóstico y Propuesta de Patrimonio Edificado en el PLAM 2035" (p. 115), por J. Hayakawa \& R. Ariza, 2015. Devenir, 2(3), 113-136.

Es una re-construcción del pasado realizada desde la actualidad por lo que está ligada al momento histórico en el que se construye, protege, gestiona o incluso destruye" (p. 14).

El reto consiste en establecer diversas formas de convivencia de los ciudadanos con aquellos monumentos aún visibles sobre la superficie, sobre todo si se considera que "Los estudios arqueológicos realizados... dan cuenta de una Lima pluricultural y pluriétnica, formada por diferentes sociedades que compartían este territorio como un lugar de encuentro y co-existencia" (Carcedo \& Advíncula, 2015, p. 100).

El patrimonio arqueológico prehispánico [en Lima Metropolitana y El Callao] (anterior a la llegada de los españoles en el s. XVI) está conformado por 538 monumentos arqueológicos. De estos, 495 están en Lima y 43 se encuentran en El Callao (19 de ellos en la isla San Lorenzo)..., existe una amplia variedad de monumentos, desde la zona arqueológica de Pachacámac, de 465.31 hectáreas,... hasta el sitio arqueológico Túpac Amaru B, de 0.06 hectáreas. (Hayakawa \& Ariza, 2015, p. 114) (Figura 1)

De esos 495 sitios registrados en Lima, más del 60\% está concentrado en los distritos que componen Lima Norte, Lima Este y Lima Sur (Hayakawa \& Ariza, 2015), y un importante grupo de restos arqueológicos se encuentra en los distritos del Cercado de Lima, Pueblo Libre y San Miguel. Uno de estos es el Complejo Maranga, un extenso centro urbano prehispánico del valle bajo del Rímac que tiene más de 1000 años de 
historia de ocupaciones, de 250 d.C. a 1532 d.C. En la actualidad, está conformado por 14 pirámides grandes y por lo menos 100 edificios pequeños que en su época de funcionamiento estuvieron rodeados de campos de cultivo, acequias y canales de regadío. Este complejo se habría extendido sobre un área de 4'000,000 m², pero, debido a la expansión de los terrenos agrícolas y el desarrollo urbano que tuvieron lugar durante el siglo XX, fue destruido y afectado. Al respecto, Del Castillo y Castro De La Borda (2015) afirman lo siguiente:

El patrimonio arqueológico en Lima está constantemente amenazado por la débil relación que los diferentes actores de la ciudad han mantenido con estos espacios a lo largo del tiempo. El crecimiento de la ciudad muestra una aparente imposibilidad por coexistir equilibradamente con sus espacios patrimoniales; se observa una predominancia del crecimiento y la expansión urbana que debilita sus conexiones urbanas y territoriales. Los espacios patrimoniales en Lima sufren de abandono, falta de interés, desconocimiento y despreocupación por parte de la sociedad, la inversión privada y el Estado. (pp. 37-38)

Sin embargo, existen aún evidencias del Complejo Maranga: las mejor conservadas se encuentran en los actuales terrenos del zoológico del Parque de las Leyendas (San Miguel), y los campus de la UNMSM (Cercado de Lima) y la PUCP (distrito de San Miguel) (Figura 2).

Este singular contexto ha facilitado una gestión institucional de los monumentos, pero siempre condicionada a factores políticos, económicos y sociales. De hecho, el manejo de las huacas del Parque de las Leyendas, a través de la división de arqueología, es un ejemplo exitoso de acondicionamiento de los monumentos precolombinos, y de creación de vínculos de convivencia con los ciudadanos. Por su parte, el manejo de los sitios ubicados dentro de los actuales terrenos de las universidades ha estado dirigido, principalmente, a la investigación en el caso de los sitios al interior de la UNMSM, y a la investigación, rescate y puesta en valor en el caso de la PUCP.

\section{Marcos institucionales de la gestión del patrimonio desde la universidad}

Durante todo el siglo XX, las constituciones políticas del Perú, las leyes, y los decretos o resoluciones supremas vinculados al patrimonio se caracterizaron por proteger o salvaguardar los bienes culturales y determinar las sanciones correspondientes en caso de afectaciones. Según lo establecido en la Ley General del Patrimonio Cultural de la Nación $\mathrm{N}^{\circ}$ 28296, promulgada en 2004, la PUCP, propietaria de terrenos donde existen bienes culturales inmuebles, tiene la obligación de protegerlos y preservarlos, y está sujeta a sanción en caso de incumplimiento. Así lo expresa el artículo 6, inciso 3 de dicha norma:

El propietario del predio donde exista un bien inmueble integrante del Patrimonio Cultural de la Nación de carácter prehispánico está obligado a registrar dicho bien, protegerlo y conservarlo, evitando su abandono, depredación y/o destrucción, conforme a las disposiciones que dicte el Instituto Nacional de Cultura [hoy Ministerio de Cultura], en las que precisa las responsabilidades comunes del Estado y del propietario del bien....El incumplimiento de estos deberes por negligencia o dolo acarrea responsabilidad administrativa, civil y penal, según corresponda.

Además, la ley en cuestión no solo determina medidas específicas en cuanto a defensa, propiedad, registro, protección y sanción, sino que también estipula las medidas que deben tomarse para la exhibición, administración y difusión del patrimonio cultural. Esta perspectiva más integral del patrimonio se vio ampliada con la creación del Ministerio de Cultura en 2010, en cuyos Lineamientos de Política Cultural se establecen vínculos entre patrimonio, desarrollo, preservación, ciudadanía e identidad:

El desarrollo de estrategias de gestión sostenible exige vincular el patrimonio con el desarrollo urbano y rural, con las comunidades y agentes culturales locales, con el turismo y con los pro- 


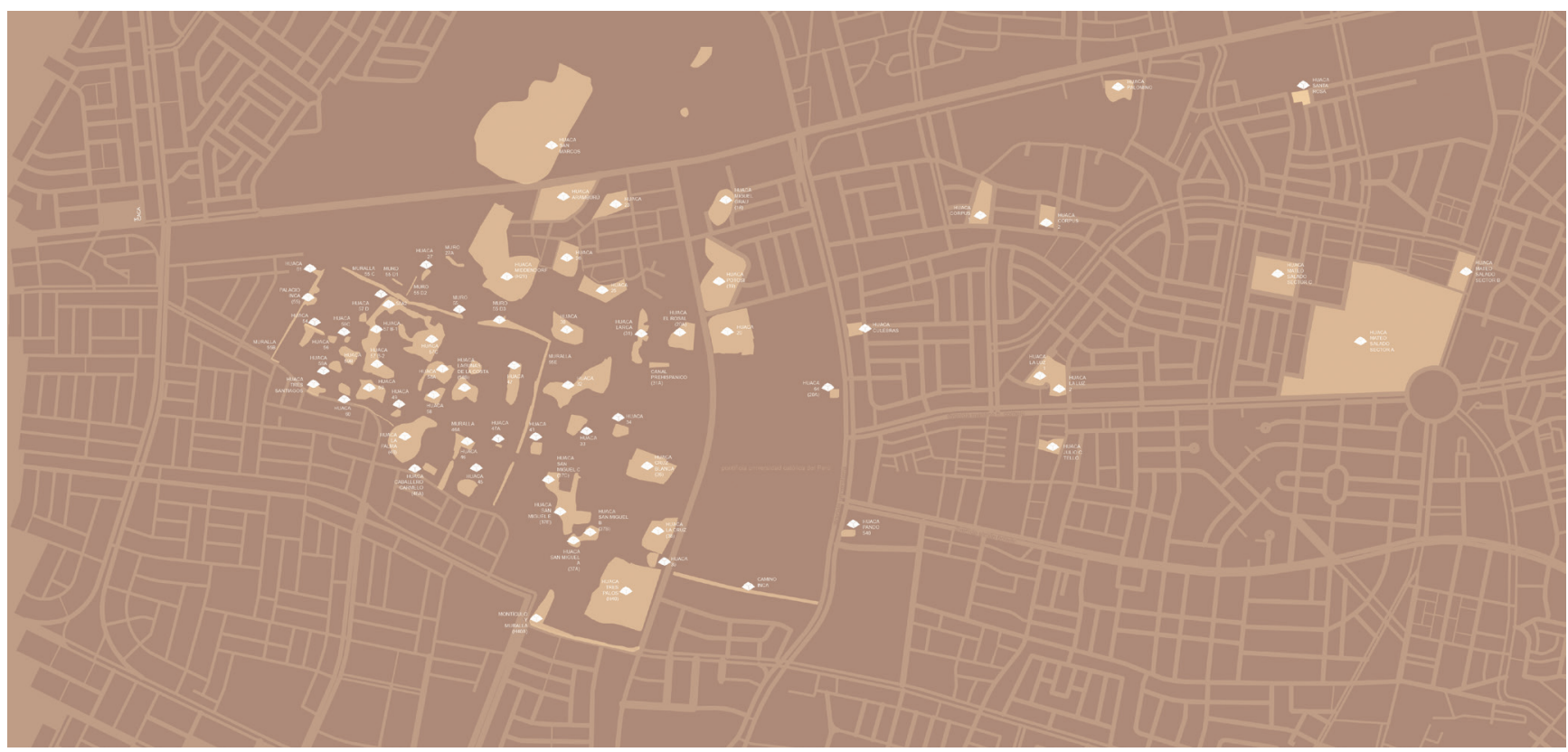

yectos interculturales que actualizan permanentemente su significación social... El Ministerio sostiene que la preservación del patrimonio tiene como principal propósito que este sea apropiado por la ciudadanía, que refuerce identidades locales y que llegue a insertarse creativamente en las políticas de desarrollo económico y social. (Ministerio de Cultura, 2012, pp. 22-23)

Complementando esta idea de sostenibilidad y apropiación, José Hayakawa (2012) señala que la preservación del patrimonio debe implicar también una serie de apuestas estratégicas como el turismo cultural, la concertación, la subsidiaridad, la planificación, la transversalidad y el desarrollo, así como proyectos de desarrollo local (p. 119).

Desde esta perspectiva, el énfasis en la gestión del patrimonio está en "conseguir una óptima conservación de los bienes patrimoniales y un uso adecuado a las exigencias sociales contemporáneas" (Ballart \& Tresserras, 2001, p. 15). El impacto social, económico, cultural y político, así como el fomento del ejercicio de la ciudadanía, el fortalecimiento de la identidad, y el reconocimiento de los valores simbólicos y de uso de los bienes patrimoniales adquieren protagonismo. Al respecto, Ballart y Tresserras (2001) sugieren tener en cuenta tres grandes categorías de valores:

- El valor de uso, referido a la satisfacción de necesidades específicas (individuales o colectivas), o como resultado de una circunstancia particular (desafío o posibilidad). Además, señalan que se diferencian valores de uso tangibles con beneficios inmediatos y directos, y valores de uso intangibles con beneficios paulatinos.

- El valor formal, asociado a la apreciación estética de los bienes.

- El valor simbólico, vinculado a la representación de personas, hechos y manifestaciones culturales. (pp. 20-21)

Cabe mencionar que los aspectos de divulgación, acceso y uso público de patrimonio fueron previamente señalados en documentos internacionales. Por ejemplo, en la $\mathrm{Cl}$ GPA (1990) se señala lo siguiente:

La protección del patrimonio arqueológico debe basarse en una colaboración efectiva entre especialistas de múltiples y diversas disciplinas.... Incluye las obligaciones de las administracio-
Figura 2. Ubicación de los actuales sitios arqueológicos del Complejo Maranga en el plano de Lima Metropolitana. Archivo digital oficina de Obras y Proyectos, Dirección de Infraestructura, Pontificia Universidad Católica del Perú. 
nes públicas y de los legisladores, las reglas profesionales aplicables a la labor de inventario, a la prospección, a la excavación, a la documentación, a la investigación, al mantenimiento, a la conservación, a la preservación, a la restitución, a la información, a la presentación, al acceso y uso público del patrimonio arqueológico, así como la definición de las cualificaciones adecuadas del personal encargado de su protección. (p. 1)

Ampliando esta definición, Pérez-Juez (2010) concluye que el reto contemporáneo de la gestión del patrimonio arqueológico considera el contexto, establece estrategias a largo plazo y, además,

Diseña programas sostenibles, desarrolla planes que sean capaces de ampliar el espectro de visitantes al que llevar el conocimiento, produce materiales específicos para cada público, forma parte de un equipo investigador y entusiasma a la inversión privada para que participe en la protección, conservación, conocimiento y divulgación del patrimonio arqueológico. (p. 25)

En este marco, los retos de la gestión del patrimonio arqueológico de la PUCP son mayores, pues no solo implican su protección y conservación de acuerdo a las normas establecidas, sino también su apropiación por parte de la comunidad universitaria; su uso en función de beneficios tangibles e intangibles; el desarrollo de programas sostenibles que involucren a investigadores, diversos públicos dentro y fuera de la universidad; e inversión en investigación, divulgación y programas educativos patrimoniales. Tal y como se menciona en la Carta de Cracovia (2000), las intervenciones en el patrimonio arqueológico deben tener en cuenta el "entorno, el territorio y paisaje" (p. 2). Como parte de dicha labor, la universidad debe por lo tanto cumplir funciones usualmente atribuidas a museos y otras instituciones responsables de la gestión del patrimonio. De acuerdo con Ballart y Tresserras (2001), estas funciones pueden tener una dimensión interna y otra pública:

Las primeras tres funciones [identificación, documentación y conservación] más el estudio constituyen la base del trabajo de cualquier institución patrimonial,.... nosotros llamaremos internas.... Las otras dos [presentación e interpretación], más el estudio o investigación, que aparece como elemento irrenunciable desde ambas facetas, tienen sobre todo que ver con la dimensión pública o social de la gestión patrimonial. (p. 23)

Las universidades, en tanto instituciones, tienen una naturaleza principalmente formativa entendida en un sentido amplio. Así lo señala el artículo 6 de la Ley Universitaria $\mathrm{N}^{\circ} 30220$, promulgada en 2014, donde se mencionan los fines de ese tipo de casa de estudios:

6.1 Preservar, acrecentar y transmitir de modo permanente la herencia científica, tecnológica, cultural y artística de la humanidad.

6.2 Formar profesionales de alta calidad de manera integral y con pleno sentido de responsabilidad social de acuerdo a las necesidades del país.

6.3 Proyectar a la comunidad sus acciones y servicios para promover su cambio y desarrollo.

6.4 Colaborar de modo eficaz en la afirmación de la democracia, el estado de derecho y la inclusión social.

6.5 Realizar y promover la investigación científica, tecnológica y humanística la creación intelectual y artística.

6.6 Difundir el conocimiento universal en beneficio de la humanidad.

6.7 Afirmar y transmitir las diversas identidades culturales del país.

6.8 Promover el desarrollo humano y sostenible en el ámbito local, regional, nacional y mundial.

6.9 Servir a la comunidad y al desarrollo integral.

6.10 Formar personas libres en una sociedad libre. 
Varios de estos fines están directamente vinculados con la gestión del patrimonio cultural $y$, de manera indirecta, bajo la perspectiva amplia que relaciona patrimonio y desarrollo, pueden ser un medio para contribuir al logro de varios otros fines, como el fortalecimiento de una ciudadanía responsable con el entorno social y cultural, el reconocimiento de identidades culturales y el desarrollo sostenible. Tal y como lo afirman Ballart y Tresserras (2001),

La preservación y el uso creativo del patrimonio cultural en el desarrollo económico y social constituyen componentes importantes del desarrollo humano sostenible y deberían utilizarse para mejorar la calidad de vida de los pueblos, particularmente de los grupos desfavorecidos, y sensibilizar a los jóvenes a través de la educación. (p. 156)

Las responsabilidades y funciones de la universidad en relación al patrimonio arqueológico que alberga en su campus están enmarcadas en las normas que rigen el funcionamiento de todas las universidades en el Perú. La existencia de sitios monumentales dentro del campus PUCP ofrece un escenario idóneo para la sensibilización de jóvenes en formación y demás miembros de la comunidad universitaria sobre los valores del patrimonio. Además, dado que dicha universidad cuenta con carreras de Humanidades, Arquitectura y Ciencias Sociales, es posible formar profesionales cuyas labores están vinculadas al patrimonio, desarrollar proyectos de investigación, y ejecutar proyectos de conservación, puesta en valor y uso social de los monumentos.

Tres universidades en Lima Metropolitana están asentadas sobre remanentes de monumentos arqueológicos: la Universidad Nacional de Ingeniería (UNI), la UNMSM y la PUCP. En la primera se encuentran las huacas UNI-CISMID y UNI-MINAS, así denominadas por el Arq. Enrique Guzmán; en la segunda, se reconocen la huaca San Marcos, y los sectores 11 y 9 de la huaca Concha; y, en la tercera, están ubicadas las huacas 20, 64 y el Camino Inca. Al igual que los otros monumentos visibles en la ciudad, estos sitios arqueológicos sufrieron daños y destrucción debido al crecimiento urbano. Por ejemplo, el estadio de la UNMSM fue construido sobre la huaca Concha y la Av. Universitaria cortó una sección del Camino Inca de la PUCP (ver Figuras 3, 4 y 5).

\section{La doctora Josefina Ramos de Cox y el Seminario de Arqueología de la PUCP}

Tal y como se señaló al inicio del texto, la particular gestión del patrimonio arqueológico desde la universidad ha estado condicionada por factores políticos, económicos y sociales, pero también a la voluntad y al compromiso de investigadores. En ese sentido, el trabajo de la doctora Josefina Ramos de Cox ha sido de especial importancia para la defensa del patrimonio cultural en el Perú y, en particular, para el inicio de la relación entre la PUCP y su patrimonio. Ramos de Cox, abogada y doctora en Letras, dirigió el Seminario de Arqueología de la Universidad entre los años 1956 y 1974, el cual estuvo conformado por grandes defensoras del patrimonio como las doctoras Mercedes Cárdenas, Inés Del Águila, Gabriela Schworbel y Hilda Vidal, entre otras. La doctora Ramos de Cox, junto con los demás miembros del seminario, realizó un importante trabajo catastral que fue entregado a la Junta Deliberante Metropolitana de Monumentos Históricos, Artísticos y Lugares Arqueológicos, gracias al cual se identificaron 23 sitios prehispánicos dispersos en los actuales distritos de San Miguel, Pueblo Libre y Cercado de Lima (Figuras 6 y 7 ).

Dicho trabajo fue significativo por varios motivos: el interés científico en el estudio de las estructuras precolombinas, la defensa del patrimonio del antiguo Complejo Maranga, y la influencia que ejerció sobre la configuración del territorio del campus de la universidad y alrededores:

Tal como describe Mogrovejo, ellas confrontaron y debatieron de manera directa a las autoridades gubernamentales y a los planes de desarrollo municipal, respectivamente, puesto que amenazaban la preservación de las estructuras prehispánicas del complejo (Mogrovejo,

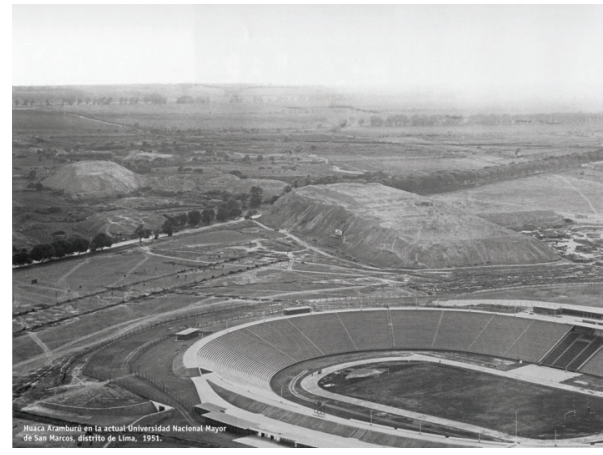

Figura 3. Huaca San Marcos y estadio de la UNMSM, 1951. En "Los orígenes de la ciudad" (p. 16), por J. Gunther \& H. Mitrani, 2013, Memorias de Lima. De haciendas a pueblos y distritos. Lima, Perú: Los Portales. 


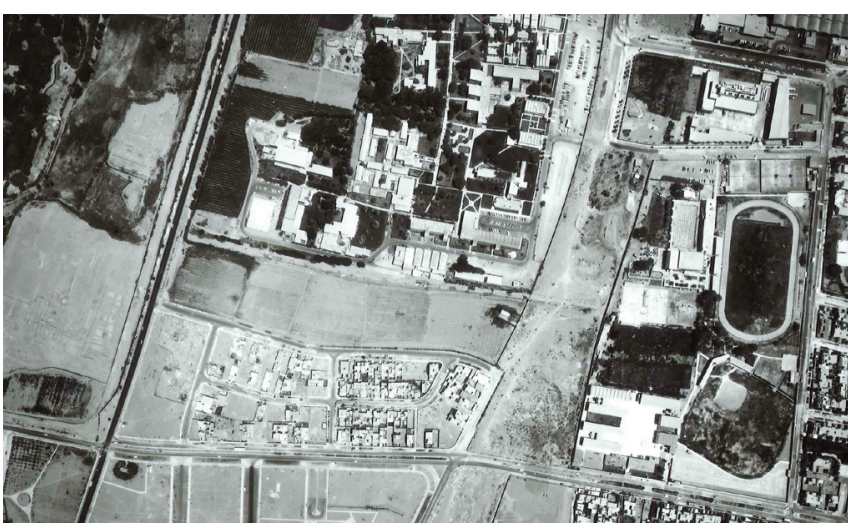

Figura 4. Vista aérea del Camino Inca, la Huaca Tres Palos y la Huaca La Cruz. Detalle de imagen del Servicio Aerofotográfico Nacional, 1986. Archivo digital oficina de Obras y Proyectos, Dirección de Infraestructura, Pontificia Universidad Católica del Perú.

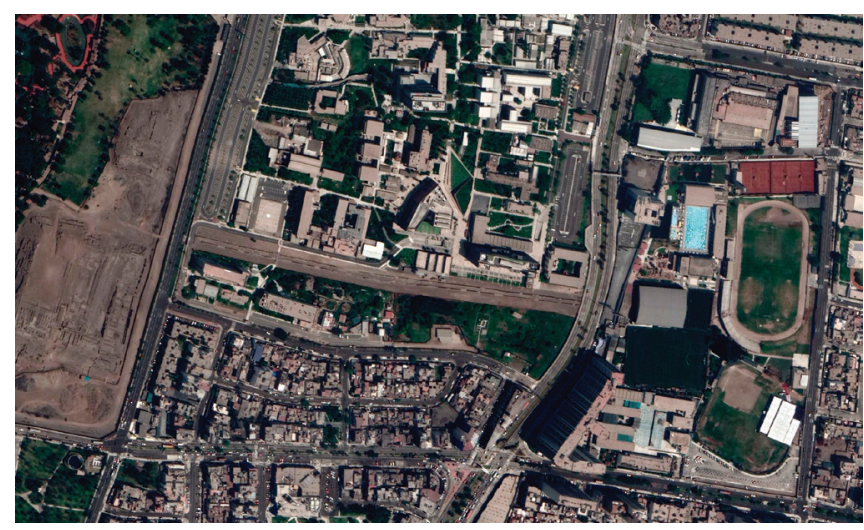

Figura 5. Vista aérea actual del Camino Inca, la Huaca Tres Palos y la Huaca La Cruz. Google Earth, 2018.

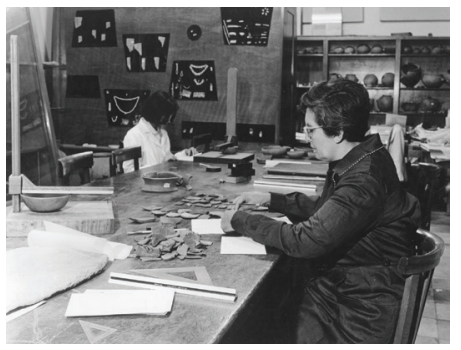

Figura 6. Doctora Josefina Ramos de Cox en el Seminario del Instituto Riva Agüero. Archivo del Seminario de Arqueología del Instituto Riva Agüero del Museo Josefina Ramos de Cox. Archivo digital oficina de Obras y Proyectos, Dirección de Infraestructura, Pontificia Universidad Católica del Perú.

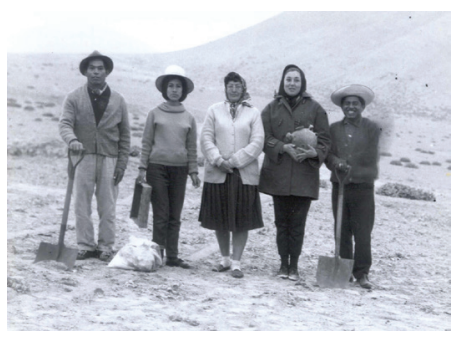

Figura 7. Tablada de Lurín, década de 1960. Integrantes del Seminario de Arqueología. Imagen del archivo del Seminario de Arqueología del Instituto Riva Agüero del Museo Josefina Ramos de Cox. Archivo digital oficina de Obras y Proyectos, Dirección de Infraestructura, Pontificia Universidad Católica del Perú.
1996)... [Estos trabajos] fueron considerados por las autoridades universitarias en la toma de decisiones sobre el diseño, cercado y organizaciones del campus, así como por las autoridades metropolitanas durante la construcción de las avenidas Universitaria y Riva Agüero. (Muro \& González Carré, 2015, pp. 21-23)

En ese sentido, Ballart y Tresserras (2001) destacan la importancia del rol de actores culturales, y su impacto en la preservación y difusión del patrimonio:

Los beneficios de una participación más diversificada en la preservación del patrimonio pueden reconocerse en la labor de asociaciones civiles, patronatos, fideicomisos y otros actores culturales de la sociedad civil. Su creciente presencia ha significado la realización de proyectos de rescate, conservación y difusión del patrimonio que de otra forma no hubiera sido posible concretar. Por su capacidad de convocar voluntades y esfuerzos, reunir recursos financieros, intermediar y realizar tareas, muchas veces en colaboración o con la asesoría de instituciones públicas, el fortalecimiento y la multiplicación de estos actores es fundamental. (p. 157)

\section{La gestión del patrimonio arqueológico de la PUCP: Huaca 20, Huaca 64 y Camino Inca}

Gracias a los trabajos iniciales llevados a cabo por la doctora Josefina Ramos de Cox, y a la voluntad política y el compromiso institucional de la PUCP con el patrimonio, se han realizado numerosos trabajos e investigaciones en los tres sitios arqueológicos ubicados denle el campus: Huaca 20, Huaca 64 y Camino Inca.

La Huaca 20 fue investigada en la década de 1970 por la doctora Mercedes Cárdenas, miembro del Seminario de Arqueología, y luego, entre los años 1996 y 2008, por diversos arqueólogos de dentro y fuera de la comunidad universitaria. Posteriormente, entre los años 2010 y 2013, fue objeto de otros proyectos de intervención a cargo de empresas de arqueología cuyos fines estuvieron orientados al rescate y liberación del sitio. Todos estos trabajos han convertido a la Huaca 20 en el sitio con el mayor número de espacios funerarios de la cultura Lima excavados sistemáticamente. Por otra parte, la Huaca 64 fue excavada a inicios de la década de 1970 por el Instituto Riva Agüero, y luego fue delimitada y excavada por Gloria Olivera y Mercedes Cárdenas en la década de 1990, junto con estudiantes de la especialidad de Arqueología de la universidad. En 2016 se llevó a cabo un proyecto de investigación, conservación y puesta en valor que incluyó el acondicionamiento del sitio para recibir visitantes. Respecto del Camino Inca, este fue inicialmente investigado por Juan Mogrovejo en la década de 1990; luego, se hicieron algunas exploraciones en 2007; y se ejecutaron proyectos de mitigación, investigación y puesta en valor entre los años 2013 y 2017. 


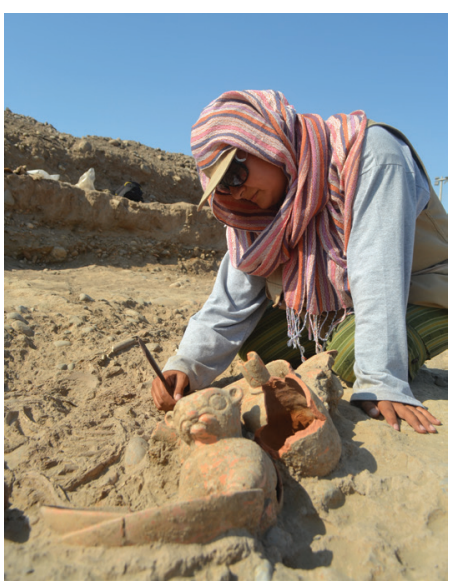

Figura 10. Tumba 37, zona IV-A, Huaca 20. Registro fotográfico del Proyecto Rescate Arqueológico - Temporada 2012-2013. Archivo digital oficina de Obras y Proyectos, Dirección de Infraestructura, Pontificia Universidad Católica del Perú.

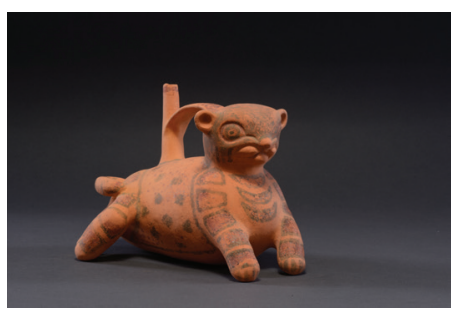

Figura 11. Vasija escultórica recuperada en la tumba 37 , zona IV-A, Huaca 20 durante el Proyecto de Rescate Arqueológico - Temporada 2012-2013 [Fotografía por M. Cayo]. Recuperado de http://repositorio.pucp.edu.pe/index/handle/123456789/112630

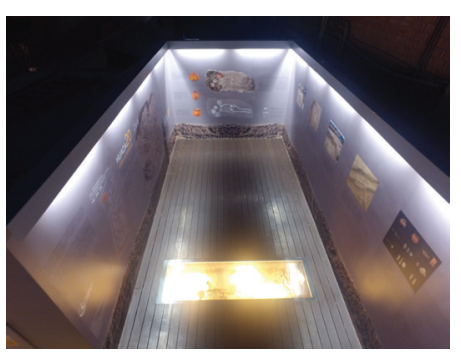

Figura 12. Módulo de exhibición que recrea la Tumba 102 y los paneles informativos. Archivo fotográfico digital de Arqueoandes S.A.C.

\section{Huaca 20}

El sitio Huaca 20, ubicado en el extremo noroeste del campus, fue un extenso asentamiento de la cultura Lima, ocupado entre los años 500 d. C. y 1100 d. C. Allí se encontraron múltiples evidencias culturales tanto de la vida cotidiana como de las prácticas funerarias de dicha población. Huaca 20 fue reconocida y catalogada gracias al Proyecto Huacas Pando, que inició en la década de 1960, tal como se mencionó líneas arriba. Las primeras excavaciones se desarrollaron en 1970, y no continuaron sino hasta la década de 1990, cuando se realizó un proyecto de investigación de dos etapas. Luego, se volvieron a retomar los trabajos entre los años 2005 y 2008, periodo en que se desarrolló tres proyectos de investigación. Posteriormente, entre los años 2010 y 2013, se ejecutaron proyectos de evaluación y rescate arqueológico con la finalidad de conocer con mayor precisión la extensión del sitio y liberar el área para futuros proyectos educativos (ver Figura 8).

El proyecto de evaluación arqueológica² se ejecutó bajo la responsabilidad de la Oficina de Infraestructura ${ }^{3}$, entre los años 2010 y 2011. Se excavaron 60 pozos de prueba a lo largo de todo el sitio y, como parte de los resultados, se determinó que el sitio se extendía sobre un área aproximada de $18,000 \mathrm{~m}^{2}$. Una vez concluida esta labor, se ejecutaron dos proyectos de rescate arqueológico ${ }^{4}$, que tuvieron como resultado la obtención de varios Certificados de Inexistencia de Restos Arqueológicos (CIRA) para un área total de $17,865.35 \mathrm{~m}^{2}$ en el campus.

Gracias a las excavaciones sistemáticas realizadas como parte de todos los proyectos de intervención mencionados, se han hallado evidencias de viviendas, vasijas y figurinas de cerámica, herramientas de pesca y textilería, todo ello testimonio inequívoco de la vida cotidiana en el asentamiento. Además, se pudo determinar que las unidades domésticas estaban relacionadas con canales y más de 800 entierros. En el marco de estos proyectos se han desarrollado numerosas investigaciones de estudiantes, y profesores de Arqueología y Bioarqueología de la PUCP, y de otras universidades extranjeras. La mayor parte de los resultados de estas investigaciones se encuentran publicados en el libro Huaca 20: Un Sitio Lima en el Antiguo Complejo Maranga. La PUCP tiene la custodia de los hallazgos producto de las excavaciones realizadas entre los años 2005 y 2013, que se encuentran en un espacio construido especialmente para su depósito, conservación e investigación. En marzo de 2018 se realizó la publicación de un catálogo de piezas enteras de Huaca 20, con el objetivo de difundir el patrimonio arqueológico mueble y motivar la investigación interdisciplinaria (ver Figuras 9 y 10 ).

Como parte de los trabajos de difusión de las investigaciones de Huaca 20 y de su integración a la vida universitaria, la PUCP implementó un módulo de exhibición que recrea uno de los 800 contextos funerarios hallados en el sitio. Mediante la réplica, se explican los aspectos más relevantes de Huaca 20, empleando paneles de gran tamaño que incluyen gráficos, imágenes y textos. Este módulo fue construido en un espacio demolido en uno de los pabellones de Ingeniería, cercano al Camino Inca. Su ubicación complementa un entorno patrimonial atractivo para la comunidad universitaria y los visitantes, y hace posible dar a conocer la larga historia de ocupaciones del Complejo Maranga en el campus (ver Figura 11).

2. El Proyecto de Evaluación Arqueológica fue aprobado mediante Resolución Viceministerial $N^{\circ}$ 203-2011-VMPCIC-MC el 16 de febrero de 2011.

3. Cabe señalar que la Oficina de Infraestructura fue acogida por la actual Dirección de Infraestructura, constituida en 2014. Esta dirección es responsable de la planificación, ejecución, supervisión y mantenimiento de la infraestructura de la universidad, de la gestión del arrendamiento de predios con fines académicos, y de la gestión del patrimonio arqueológico e histórico. Para esto último, cuenta con un puesto de arqueólogo en el campus universitario.

4. El primer Proyecto de Rescate Arqueológico fue aprobado mediante Resolución Directoral 167-DGPC-VMPCIC/MC de fecha 04/08/2011; y el segundo, mediante Resolución Directoral N803 -2012 DGPC - VMPCIC/MC de fecha 26/10/2012. 


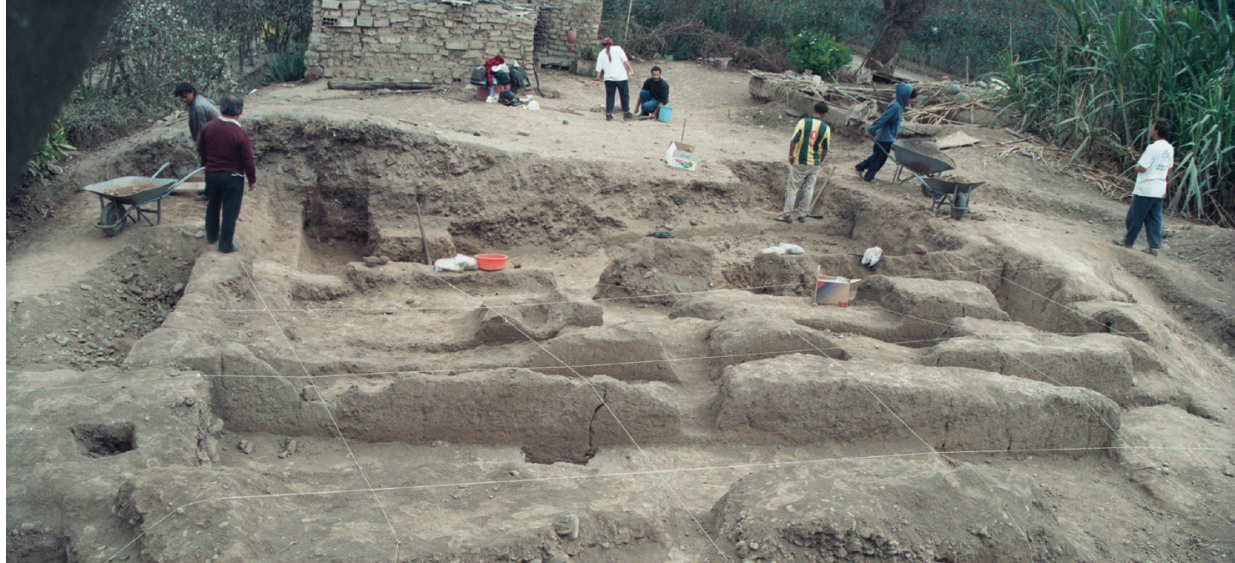

Figura 13. Vista de las excavaciones de la Huaca 64 de 1996 [Fotografía por R. Santa Cruz]. En Informe final del Proyecto Investigación Arqueológica con fines de Conservación y Puesta en Valor de la Huaca 64, ubicada en el campus de la Pontificia Universidad Católica del Perú. Fuente: Archivo digital oficina de Obras y Proyectos, Dirección de Infraestructura, Pontificia Universidad Católica del Perú.

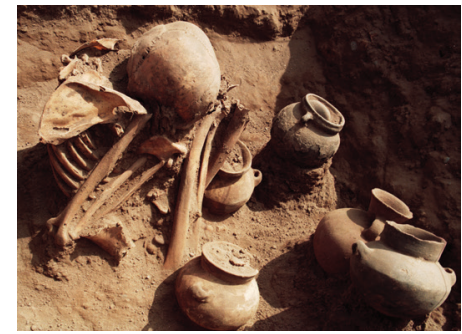

Figura 14. Vista del principal hallazgo de la Huaca 64 durante las excavaciones de 1996 [Fotografía por $R$. Santa Cruz]. En Informe final del Proyecto Investigación Arqueológica con fines de Conservación y Puesta en Valor de la Huaca 64, ubicada en el campus de la Pontificia Universidad Católica del Perú. Archivo digital oficina de Obras y Proyectos, Dirección de Infraestructura, Pontificia Universidad Católica del Perú.

\section{Huaca 64}

La Huaca 64 se encuentra en el lado noreste del campus, junto al edificio de maestranza. El sitio, que abarca una superficie de $524.15 \mathrm{~m}^{2}$, fue declarado Patrimonio Cultural de la Nación por Resolución Viceministerial Nº12-2012 el 24 de febrero de 2012. Está constituido por una terraza elevada ampliada en al menos tres momentos, un pasadizo por donde accedían las personas desde el exterior, y un patio que fue construido mediante una excavación por debajo de la superficie de uso, una técnica poco común.

Al parecer, se trató de un espacio de reunión de grupos sociales locales liderados por un líder o curaca, que estuvo en funcionamiento alrededor del año 1,100 d.C., durante la época ychsma. En el patio se hallaron evidencias de grandes vasijas que probablemente contenían chicha. Los incas, al llegar a esta parte de la costa central, reutilizaron el espacio, y colocaron un entierro intrusivo de una mujer adulta dentro la terraza elevada o plataforma.

Las primeras investigaciones en esta huaca se realizaron entre agosto y diciembre de 1996, y estuvieron a cargo de la doctora Mercedes Cárdenas, profesora de la especialidad de Arqueología de la PUCP. Estos trabajos se realizaron como parte de un reconocimiento y evaluación científica solicitado por la Dirección de Administración de la universidad con el objetivo de construir los ambientes para maestranza. Como resultado de esta labor, se logró delimitar y proteger el sitio, se definió la mayor parte de la arquitectura, y se determinó la ubicación cronológica tardía de la Huaca 64 gracias al hallazgo del entierro de la mujer adulta, donde se hallaron vasijas de estilo ychsma a la altura de sus pies y un aríbalo inca a la altura de su cabeza (ver Figuras 12 y 13).

Luego, entre enero y diciembre de 2016, se ejecutó el Proyecto de Investigación Arqueológica con Fines de Conservación y Puesta en Valor de la Huaca $64^{5}$, el cual tuvo por objetivo proteger y conservar el monumento, difundir la información científica al respecto e integrarlo al paisaje del campus universitario. Gracias a esta segunda intervención en la huaca, se logró complementar la información obtenida en 1996, y se definió la dinámica de circulación del sitio. Además, se establecieron medidas especializadas de conservación como pruebas de salinidad, inyección de barro, creación de pisos de sacrificio y restitución de elementos, para brindar una mejor apreciación

5. El Proyecto Investigación Arqueológica con Fines de Conservación y Puesta en Valor de la Huaca 64 fue aprobado mediante Resolución Directoral № 058-2016/DGPA/VMPCIC/MC el 18 de febrero de 2016. 


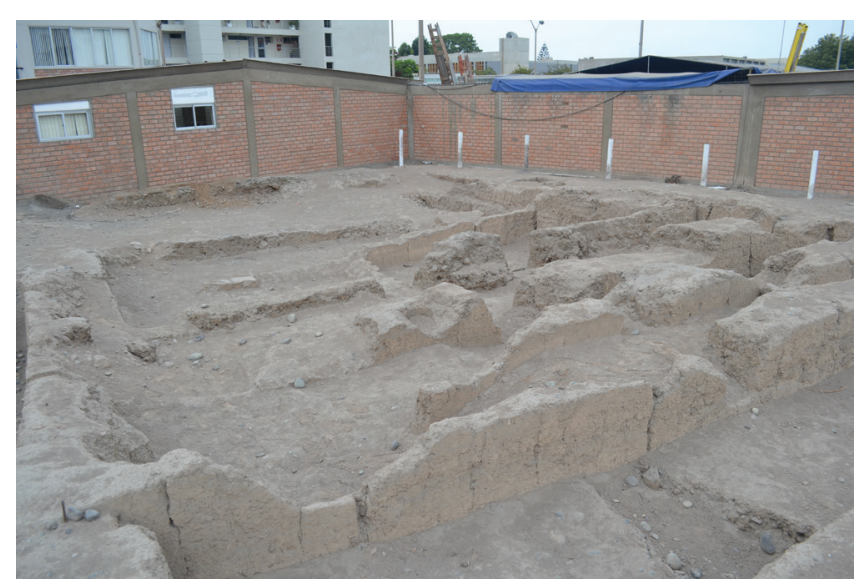

Figura 15. Vista de las excavaciones de la Huaca 64 antes de 1996 [Fotografía por R. Santa Cruz]. En Informe final del Proyecto Investigación Arqueológica con fines de Conservación y Puesta en Valor de la Huaca 64, ubicada en el campus de la Pontificia Universidad Católica del Perú. Archivo digital oficina de Obras y Proyectos, Dirección de Infraestructura, Pontificia Universidad Católica del Perú.

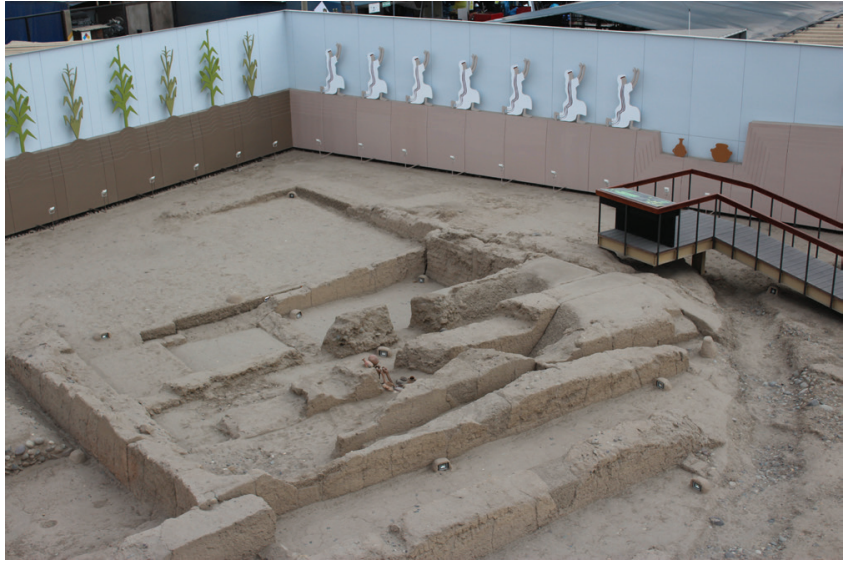

Figura 16. Vista de la Huaca 64 después de la intervención de puesta en valor [Fotografía por R. Ríos]. Archivo digital oficina de Obras y Proyectos, Dirección de Infraestructura, Pontificia Universidad Católica del Perú.

y comprensión del monumento. Se colocaron réplicas de los principales hallazgos recuperados en las primeras excavaciones, y unos paneles que rodean el sitio con escenografías que recrean el espacio y las principales actividades que se desarrollaban en la huaca. A esto se sumó la construcción de una pasarela en forma de rampa, que termina en un descanso con un panel informativo sobre el sitio, las investigaciones y los principales hallazgos. Esta pasarela permite que los visitantes puedan acercarse al monumento y observarlo en toda su extensión desde una perspectiva de planta, lo que permite comprender la distribución de la arquitectura en el espacio. El panel informativo cuenta con un audio con música de instrumentos de viento fabricados con réplicas de vasijas precolombinas, y una voz que narra la historia de la huaca.

Asimismo, la instalación en torno a la Huaca 64 cuenta con otro elemento gráfico informativo, denominado, ubicado en el extremo noreste, afuera del monumento, donde se presentan mapas, fotografías e información complementaria a la presentada en el panel informativo colocado en la pasarela. Finalmente, la intervención integral de puesta en valor incluyó la implementación de un sistema de iluminación ornamental que realza las características del monumento durante la noche y hace posible realizar visitas nocturnas (ver Figuras 14 y 15).

\section{Camino Inca}

El otro monumento que forma parte del Complejo Maranga es el Camino Inca, ubicado en la parte sur del campus de la Universidad. Se trata de una vía amurallada de 467 metros de longitud que estuvo integrada a la red de caminos inca en el valle del Rímac, la cual permitía la conexión de importantes sitios administrativos y religiosos como las huacas del Parque de las Leyendas y el Complejo Arqueológico Mateo Salado. EI trazo inicial del camino se realizó durante la época ychsma, y luego fue integrado a la red vial inca entre 1450 y $1530 \mathrm{~d}$. C. Tiene paredes de hasta cuatro metros de altura y no se han registrado entradas ni salidas en su trayectoria, por lo que se presume que pudo haber sido reservado para miembros de las élites en peregrinación religiosa a santuarios o misiones oficiales. El Camino Inca fue delimitado y declarado Patrimonio Cultural de la Nación mediante Resolución Directoral Nacional № 233/INC № en 2007, y su clasificación oficial cambió a Paisaje Cultural Arqueológico en junio de 2010 por Resolución Directoral Nacional № 1522/INC. 
En el Informe final del Proyecto Investigación Arqueológica con Fines de Conservación y Puesta en Valor del Camino Inca en la Pontificia Universidad Católica del Perú se menciona lo siguiente:

Una de las primeras referencias bibliográficas que se hace al Camino prehispánico ubicado en el campus de la PUCP es ofrecida por Ernst Middendorf en 1894, quien distingue tres caminos en el Complejo Maranga, donde además indica que el camino que corre en dirección Oeste se extendía aproximadamente tres kilómetros (Middendorf, 1973, p. 58). (Del Carpio, Villacorta \& De las Casas, 2014, p. 5)

Las primeras investigaciones en este camino fueron realizadas por Juan Mogrovejo en 1995, en el marco de un proyecto de investigación, conservación y puesta en valor de los monumentos al interior del campus. Como parte de los trabajos, se llevó a cabo acciones de limpieza del camino, se presentó planos y fotografías, y describió las principales características del Camino Inca. Posteriormente, Carlos Rengifo dirigió otro proyecto de investigación entre 2006 y 2007, que implicó la realización de algunos cateos, pero no se encontró evidencias significativas. Posteriormente, durante 2013 se ejecutaron tres proyectos en relación al Camino Inca: el primero fue un plan de monitoreo en el marco de la construcción del edificio Aulario y estacionamientos; el segundo, un plan de mitigación que acompañó el plan de monitoreo; y el tercero, un proyecto de investigación, conservación y puesta en valor ${ }^{6}$. Este último tuvo por objetivo contribuir a la investigación y conservación integral del monumento. Gracias a estas labores, se determinó que habría tenido tres fases constructivas: la primera, cuando se construyó el camino sobre una plataforma elevada en la época ychsma; la segunda, en la época inca, cuando se destruyó parte de este trazo inicial y se reutilizó los restos como parte del relleno del nuevo camino para hacer una modificación de la dirección hacia el Sur y aumentar la altura en los muros que lo flanquean; y la tercera, cuando se construyó algunos paños con perforaciones en muros para colocar madera rolliza, ya en época colonial tardía o republicana (ver Figuras 16 y 17).

Otro aspecto importante de este último proyecto fue el tratamiento integral de conservación que se realizó en el monumento. Se intervino en 936 paños de los muros que flanquean el camino: se realizó una limpieza superficial de paramentos y cabeceras de muros, así como la consolidación estructural de todos los muros, se restituyó de la verticalidad de los paños, y se realizó la reposición y reintegración de fragmentos de tapial. Asimismo, se rellenaron agujeros provocados por insectos, y se limpió y dio un tratamiento especial a los esgrafiados y grafitis. También se emparejó el terreno, y se trató el suelo de la calzada y las áreas externas. En cuanto a la limpieza general, se retiraron árboles, escombros, basura contemporánea y desmonte (ver Figura 18).

En una segunda etapa de puesta en valor del Camino Inca, se desarrolló un concurso para elaborar una propuesta paisajística cuyo objetivo fuese la protección del monumento y su asimilación por la comunidad universitaria. La propuesta ganadora fue ideada por el arquitecto Manuel Flores, docente de la PUCP. Esta incluyó, entre otros planteamientos, el colocar un borde de tierra de protección en los lados externos de los muros que flanquean el camino; la construcción de dos alamedas longitudinales paralelas al borde de tierra que permitan una circulación peatonal cercana al monumento, que facilite su contemplación; el emplazamiento de dos puentes peatonales que permitan conectar todo el campus con el lado sur del mismo; y el desarrollo de un proyecto de iluminación e implementación de paneles informativos. Esta propuesta ha sido revisada y aprobada por el Ministerio de Cultura con algunas recomendaciones generales (ver Figura 19).

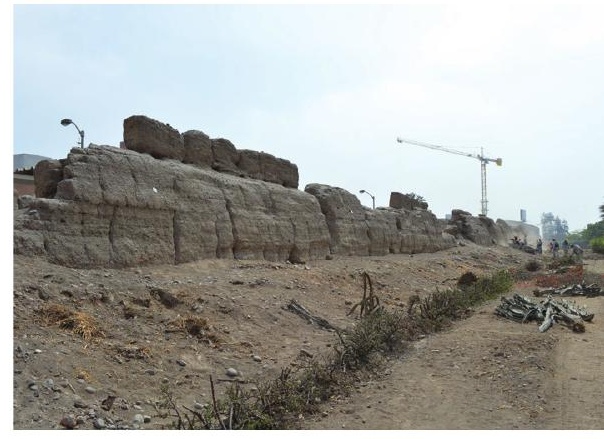

Figura 17. Vista del flanco exterior del muro sur del Camino Inca antes de la intervención en el marco del proyecto de investigación, conservación y puesta en valor del Camino Inca. Archivo digital oficina de Obras y Proyectos, Dirección de Infraestructura, Pontificia Universidad Católica del Perú.

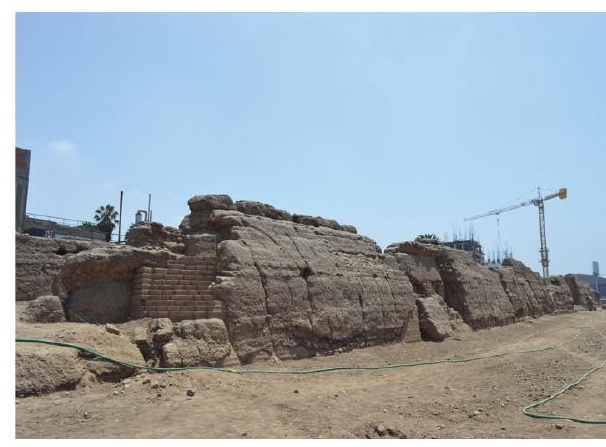

Figura 18. Vista del flanco exterior del muro sur del Camino Inca después de la intervención en el marco del proyecto de investigación, conservación y puesta en valor del Camino Inca. Archivo digital oficina de Obras y Proyectos, Dirección de Infraestructura Pontificia Universidad Católica del Perú.

6. El Proyecto Investigación Arqueológica con Fines de Conservación y Puesta en Valor del Camino Inca fue aprobado mediante Resolución Directoral N 185-2013/DGPA/VMPCIC/MC el 14 de octubre de 2013. 


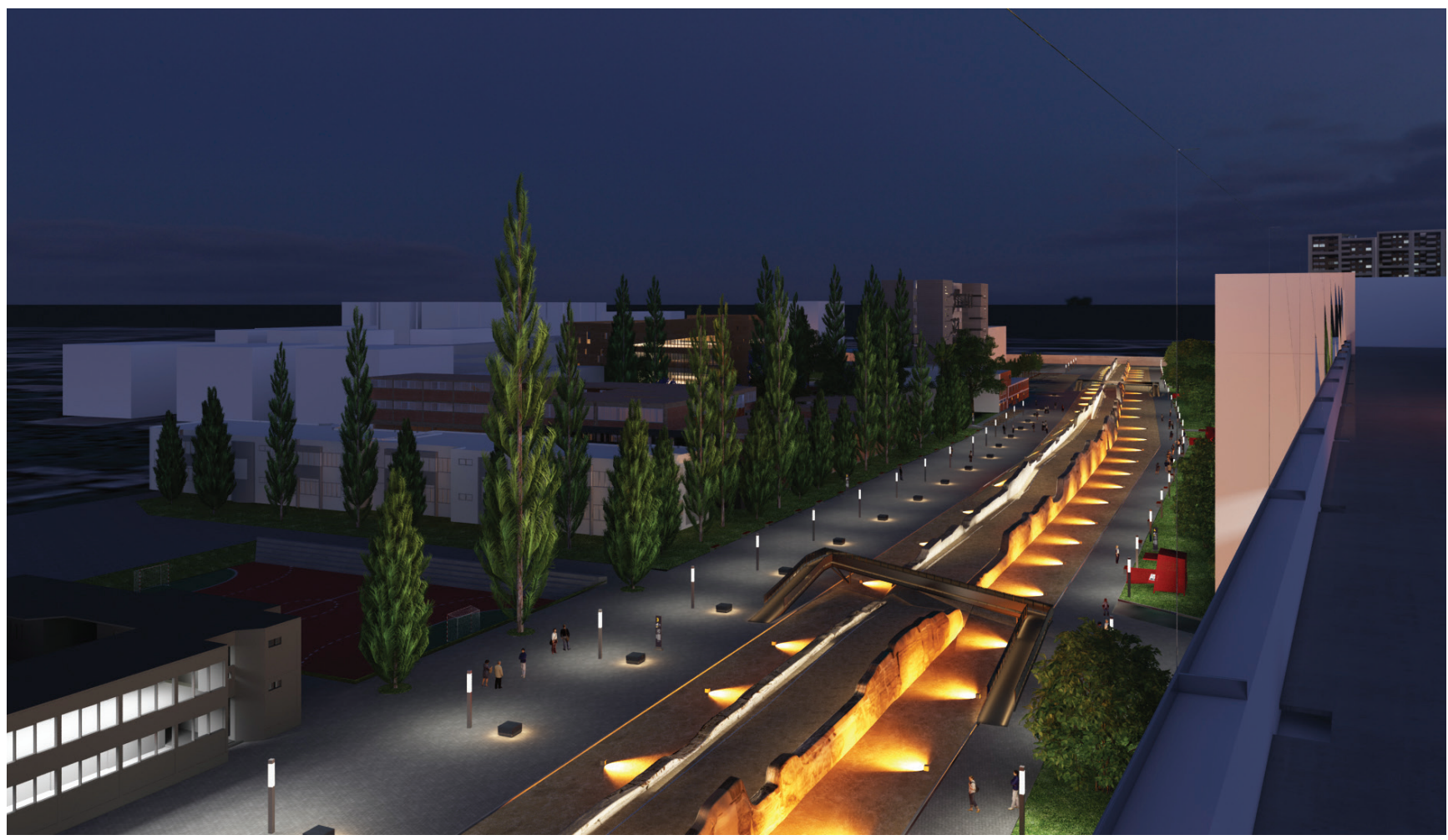

Siguiendo lineamientos similares, los nuevos y modernos edificios ubicados en la zona sur del campus han sido diseñados teniendo en consideración el patrimonio arqueológico presente. Tal y como se mencionó líneas arriba, el edificio Aulario cuenta con espacios y paneles especialmente diseñados que ofrecen información sobre la historia de Camino Inca. Además, en el último piso de este edificio se tiene planificado el desarrollo de un centro de interpretación donde se brinde mayor información científica acerca del monumento prehispánico. Asimismo, la nueva biblioteca del Complejo de Innovación Académica (CIA) incluye hornacinas distribuidas en varios pisos del edificio destinadas a albergar piezas arqueológicas de las colecciones del Museo Josefina Ramos de Cox, perteneciente al Instituto Riva Agüero de la PUCP .

Otro aspecto que denota que la gestión del patrimonio ha formado parte del quehacer institucional de la universidad es que los proyectos de construcción de obras de la universidad que implican excavaciones se desarrollan en el marco de Planes de Monitoreo Arqueológico, según lo estipulado en el Reglamento de Intervenciones Arqueológicas aprobado por Decreto Supremo № 003-2014. Tal y como se señala en el artículo 11, inciso 15 de dicha norma, los planes de monitoreo arqueológico: "Son intervenciones arqueológicas destinadas a implementar medidas para prevenir, evitar, control, reducir y mitigar los posibles impactos negativos sobre vestigios prehispánicos..., en el marco de ejecución de obras de infraestructura y servicios" (ver Figura 20).

Finalmente, como parte de las tareas de difusión del patrimonio arqueológico, durante 2017 se desarrollaron algunas visitas guiadas a los sitios mencionados, orientadas a miembros de la comunidad universitaria, entre estudiantes, docentes y trabajadores (ver Figuras 21y 22).

7. Además, en otros pisos de dicha biblioteca hay hornacinas para albergar piezas del Museo de Arte y Tradiciones Populares, perteneciente al Instituto Riva Agüero de la universidad.

Figura 20. Vista 3D de puente peatonal [Elaborada por M. Flores]. Archivo digital oficina de Obras y Proyectos, Dirección de Infraestructura, Pontificia Universidad Católica del Perú. 


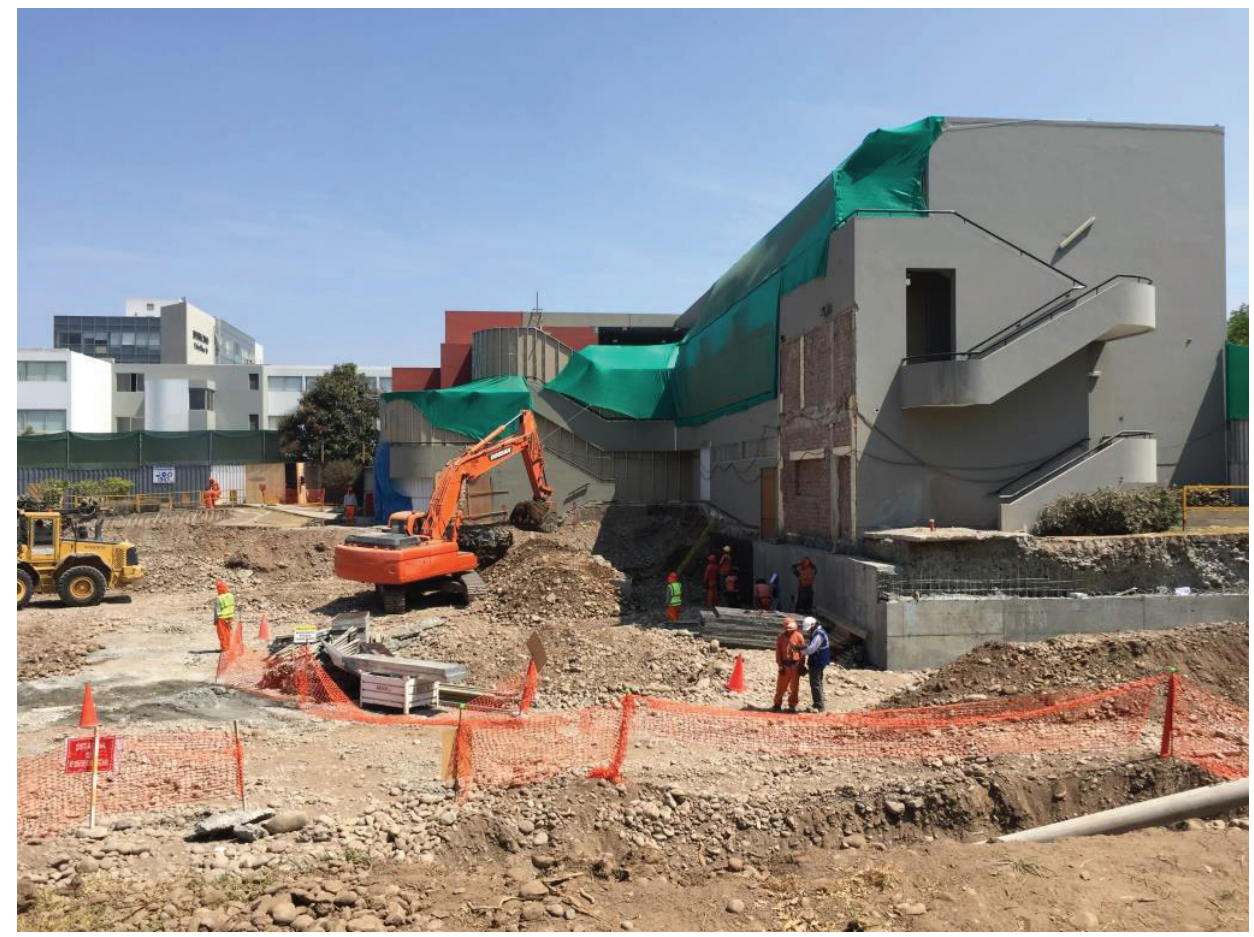

Figura 21. Vista de la obra del nuevo complejo, la cual contó con un plan de monitoreo arqueológico. En Informe Final del Plan de Monitoreo Arqueológico (PMA) durante las Excavaciones y Remoción Masiva de Tierra para la Construcción del "Complejo de Ciencias Sociales - PUCP" (p. 22), por J. Sánchez, 2017. Archivo digital oficina de Obras y Proyectos, Dirección de Infraestructura, Pontificia Universidad Católica del Perú.

\section{Conclusiones}

Los sitios arqueológicos ubicados en el campus de la PUCP forman parte de los múltiples fragmentos de historia materializada dentro de la traza urbana de Lima Metropolitana. Las investigaciones en torno a estos monumentos, correspondientes al extenso y milenario Complejo Maranga, sugieren una historia de más de 900 años de ocupaciones y reocupaciones, de la vida cotidiana de las sociedades y de la vida pública, de remodelaciones, de adaptaciones y de rituales. Es importante tener en cuenta el valor simbólico de estos bienes patrimoniales en la difusión de la herencia cultural, y fortalecer la memoria colectiva.

En cuanto al aspecto institucional, los marcos legales establecen la responsabilidad que tiene la universidad de proteger y preservar los bienes culturales existentes en su territorio y, las respectivas sanciones en caso de incumplimiento. Además, la gestión integral del patrimonio supone no solo acciones de conservación, sino también su utilización (tangible e intangible) según las necesidades actuales. La universidad debe cumplir funciones usualmente atribuidas a museos y otras instituciones responsables del patrimonio: identificación, documentación, conservación, estudio, presentación e interpretación. Todas estas responsabilidades se condicen con lo expresado en la Ley Universitaria peruana; por ello, la gestión del patrimonio arqueológico debería ser una de las prioridades institucionales. En ese sentido, un desafío importante consiste en construir una política, y un plan de gestión del patrimonio cultural presente en el campus de la universidad a mediano y largo plazo.

A partir de los trabajos realizados por la doctora Josefina Ramos de Cox junto a los miembros del Seminario de Arqueología en los años 60, la PUCP inició una relación con su patrimonio que se ha traducido en diversas actuaciones, según el contexto político, 


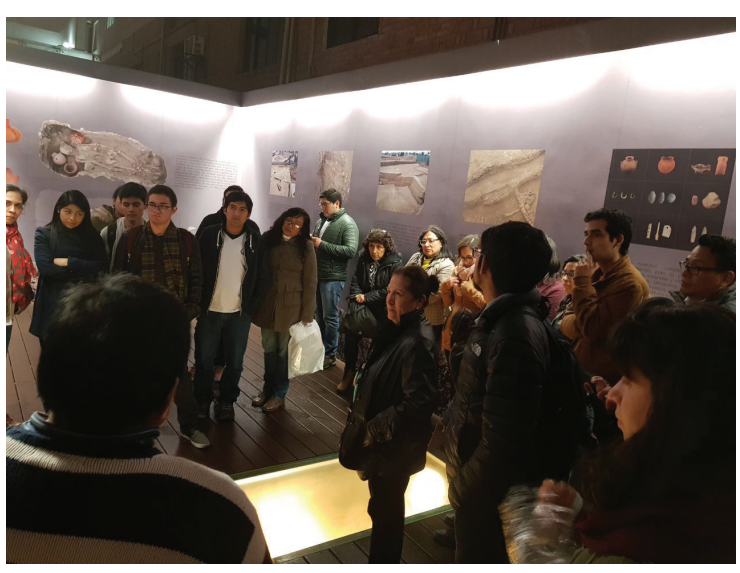

Figura 22. Vista guiada - Módulo de exhibición de huaca 20. [Fotografía por A. Su]. Archivo digital oficina de Obras y Proyectos, Dirección de Infraestructura, Pontificia Universidad Católica del Perú.

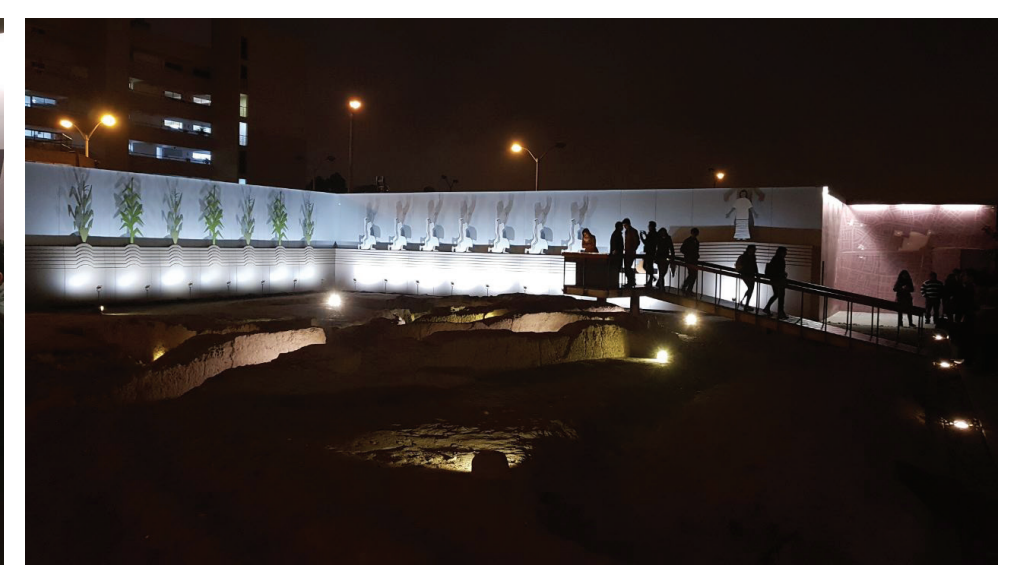

Figura 23. Vista guiada - Huaca 64 . [Fotografía por A. Su]. Archivo digital oficina de Obras y Proyectos, Dirección de Infraestructura, Pontificia Universidad Católica del Perú.

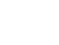

económico y social. Desde entonces han tenido lugar periodos de inacción y olvido, pero especialmente desde el año 2010 se han llevado a cabo intervenciones de gran envergadura en los sitios arqueológicos ubicados en el campus. El compromiso de la PUCP con su patrimonio se expresa en la voluntad política de las autoridades, la configuración de sus direcciones y unidades, la asignación de recursos para la ejecución de intervenciones arqueológicas, su inclusión en el plan maestro de crecimiento de la universidad, y el cumplimiento de las normas de protección y defensa del patrimonio.

La PUCP ha orientado la gestión del patrimonio arqueológico hacia el cumplimiento de funciones de dimensión interna, como la identificación, documentación, conservación y estudio. Estas tareas se han desarrollado en los tres sitios arqueológicos: Huaca 20, Camino Inca y Huaca 64. En cambio, las tareas vinculadas a la dimensión pública o social son iniciales. Entre estas se puede mencionar el acondicionamiento parcial del Camino Inca, la intervención integral en la Huaca 64 para el disfrute de la comunidad, la construcción de edificios diseñados en relación con el Camino Inca, la exhibición de bienes culturales muebles y realización de visitas guiadas. Sin embargo, aún se mantienen los desafíos de difundir e integrar el patrimonio arqueológico a la vida cotidiana de la comunidad universitaria, teniendo en consideración los valores de uso, formal y simbólico. Al reconocer estos valores, y cruzarlos con las responsabilidades y funciones de la universidad en relación con su patrimonio, se visibiliza la importancia de realizar acciones sostenibles en el tiempo que contribuyan a fortalecer la identidad y el ejercicio de la ciudadanía.

\section{Referencias}

Carta de Cracovia. (2000). Principios para la conservación y restauración del patrimonio construido.

Del Castillo, J. M. \& Castro de la Borda, M. (2015, julio-diciembre). La estrategia de integración de espacios abiertos y patrimonio en el plan metropolitano de desarrollo urbano Lima-Callao 2035. Devenir, 2(4), 27-44.

Del Carpio, M.; De las Casas, G.; \& Ramírez, M. (2016). Informe final del Proyecto investigación arqueológica con fines de conservación y puesta en valor de la Huaca 64, ubicada en el campus de la Pontificia Universidad Católica del Perú [Informe presentado al Ministerio de Cultura].

Del Carpio, M.; Villacorta, L. F.; \& De las Casas, G. (2014). Informe final del Proyecto Investigación Arqueológica con Fines de Conservación y Puesta en Valor del Camino Inca en la Pontificia Universidad Católica del Perú [Informe presentado al Ministerio de Cultura].

Ley N³ 30220. Ley Universitaria. (9 de julio de 2014). El Peruano. 
devenir Vol. 5, Nº10, JULIO-DICIEMBRE 2018, PP. 91-108 - EstudIOS | ISSN 2312-7562 | E-ISSN 2616-4949

UNIVERSIDAD NACIONAL DE INGENIERÍA, LIMA

Gunther, J. \& Mitrani, H. (2013). Los orígenes de la ciudad. En Memorias de Lima. De haciendas a pueblos y distritos. Lima, Perú: Los Portales.

Guzmán, E. (2015). Huacas de la Universidad Nacional de Ingeniería y la verdadera Huaca Aliaga. Devenir, 2(4), 104-126.

Hayakawa, J. (2012). Restauro UNI: Breve antología de textos de restauración del patrimonio monumental edificado. Lima, Perú: Universidad Nacional de Ingeniería.

Hayakawa, J. \& Ariza, R. (2015). Patrimonio y plan urbano en Lima: apuestas y desafíos del diagnóstico y propuesta de patrimonio edificado en el PLAM 2035. Devenir, 2(3), 113-136.

International Council on Monuments and Sites. (1990). Carta Internacional para la Gestión del Patrimonio Arqueológico.

Mauricio, A.; Muro, L.; \& Olivera, C. (2015). Huaca 20: Un sitio Lima en el antiguo Complejo Maranga. Lima, Perú: Instituto Francés de Estudios Andinos y Pontificia Universidad Católica del Perú.

Matos, R. \& Williams, C. (1986). Preservación y promoción del Patrimonio Monumental. En Patrimonio Cultural del Perú. Balance y perspectivas (pp. 37-74). Lima, Perú: Fomciencias.

Millones, L. (1986). Patrimonio cultural: planteamientos para una nueva perspectiva y propuesta de acción. En Patrimonio Cultural del Perú. Balance y perspectivas (pp. 27-35). Lima, Perú: Fomciencias.

Ministerio de Cultura. (2017). Política Nacional de Cultura. Tú también creas la Política Nacional de Cultura. Documento de diagnóstico: Estado general del sector cultura en el Perú. Recuperado de https://politicanacional.cultura.gob.pe/doc/fase/diagnostico.pdf

Ministerio de Cultura. (2012). Lineamientos de Política Cultural. 2013-2016. Versión preliminar. Recuperado de https://www.cultura.gob.pe/sites/default/files/pagbasica/tablaarchivos/11/ lineamientomc.pdf

Muro, L. \& González Carré, E. (2015). Cuarenta años de excavaciones en el sitio arqueológico Huaca 20 y los nuevos retos de la gestión del patrimonio arqueológico de la PUCP. En Huaca 20: Un sitio Lima en el antiguo Complejo Maranga (pp. 161-174). Lima, Perú: Instituto Francés de Estudios Andinos.

Ossio, J. (1986). Diagnóstico sobre la situación del Patrimonio Cultural del Perú. En Patrimonio Cultural del Perú. Balance y perspectivas (pp. 17-23). Lima, Perú. Fomciencias.

Pérez-Juez, A. (2010). La gestión del patrimonio arqueológico: De la tradición al nuevo panorama del siglo XXI. En La ciudad dentro de la ciudad: La gestión y conservación del patrimonio arqueológico en ámbito urbano (pp. 9-26). Sevilla, España: Universidad Pablo de Olavide.

Rengifo, C. (2006). Proyecto arqueológico Huaca 20-Complejo Maranga. Informe de investigaciones. Temporada 2005 [Informe presentado al Ministerio de Cultura].

Sánchez, J. (2017). Plan de monitoreo arqueológico (PMA) durante las excavaciones y remoción masiva de tierra para la construcción del "Complejo de Ciencias Sociales - PUCP" [Informe presentado al Ministerio de Cultura].

Sánchez, J. (2018). Plan de monitoreo arqueológico (PMA) para el "Proyecto de canalización eléctrica y data - Zona sur PUCP" [Informe presentado al Ministerio de Cultura].

Sasaki Associates. (2014). Plan Maestro de la PUCP al 2030. Recuperado de http://vicerrectorado. pucp.edu.pe/administrativo/wp-content/uploads/2014/11/MarcoPaisajistico.pdf

TV Perú HD. (2017, 11 de julio). Las Huacas de Lima. Sucedió en el Perú [Archivo de video]. Recuperado de https://youtu.be/yVI75Rnd8Cl

Valencia, F. (16 de junio de 2008). El tráfico ilícito de bienes culturales del Perú. Recuperado de http://blog.pucp.edu.pe/blog/aleajactaes/2008/06/16/el-trafico-ilicito-de-bienes-culturales-en-el-peru/

Villacorta, L. (2013) Informe final Rescate Arqueológico en el sitio arqueológico Huaca 20, Complejo Maranga, Campus de la Pontificia Universidad Católica del Perú. Temporada 2012-2013 [Informe presentado al Ministerio de Cultura]. 